\title{
Can Naphthalene Exposure Stress Alter Brain Biogenic Amine Levels Before and during Vitellogenesis in Liza klunzingeri Fish?
}

Zahra Yarahmadi ${ }^{1}$, Abdolali Movahedinia ${ }^{1}$, Ahmad Savari $^{1}$, Morteza Behnam Rassouli ${ }^{2}$, Mohammadreza Sahraeian ${ }^{3}$, Hossein Pasha Zanoosi ${ }^{4}$ and Sara Rastgar*1

${ }^{1}$ Department of Marine Biology, Faculty of Marine Sciences, Khorramshahr University of Marine Science and Technology, Khoozestan, P.O.Box: 669, Iran ${ }^{2}$ Department of Biology, Faculty of Sciences, Ferdowsi University of Mashhad, Iran

${ }^{3}$ Emam Khomini Marine Fish Research Station, Khoozestan, Iran

${ }^{4}$ Department of Physical Oceanography, Khorramshahr University of Marine Science and Technology, Khoozestan, Iran

\begin{abstract}
In this study, effects of naphthalene (NAP) exposure on plasma levels of $17-\beta$ estradiol and concentrations of neurotransmitters in different brain regions of female Klunzinger's mullet, at the previtellogenic and vitellogenic stages were examined. Studied neurotransmitters were noradrenalin (NA), serotonin (5-HT), dopamine (DA), and 3,4-dihydroxyphenylacetic acid (DOPAC) and 5-hydroxy-3-indoleacetic acid (5HIAA). In the short- term stress experiment, fish were i.p. injected with $2 \mu \mathrm{l} / \mathrm{g}$ vegetable oil alone (control) or oil containing NAP ( $50 \mathrm{mg} / \mathrm{kg}$ body weight). To study the long-term effect of NAP an amount of $(50 \mathrm{mg} / \mathrm{kg}$ NAP $+10 \mu \mathrm{l} / \mathrm{g}$ coconut oil) as i.p. implant and $10 \mu \mathrm{l} / \mathrm{g}$ coconut oil alone for control group. After long-term exposure, $17-\beta$ estradiol level in the plasma decreased in both stages fish. Monoamines analyses showed changes induced by NAP which depended upon the type of neurotransmitter and exhibited a marked brain regional selectivity. According to the results, NAP had more disturbing effects at the previtellogenic than the vitellogenic stages. Serotonergic system responded to the NAP exposure rapidly whereas dopaminergic system changed during the chronic naphthalene stress. The mentioned disturbing effects of naphthalene on the brain monoaminergic systems may cause some endocrine disruptions especially in the hypothalamus-pituitarygonad axis and finally affect the vitellogenesis process and final oocyte maturation. Reduction in the plasma levels of $17-\beta$ estradiol during the naphthalene exposure probably are related biological feedbacks of neurotransmitters on the pituitary.
\end{abstract}

Keyword: Naphthalene; Stress; Neurotransmitters; $17-\beta$ estradiol; Liza klunzingeri.

\section{Introduction}

Generation requires a successful reproduction in living organisms. In mature ovaries of female fish vitellogenesis is an important physiological process during which ova store yolk [1]. This process is started by gonadotropin hormones released from pituitary into the blood stream. The conversion of androgens into $17 \beta$ - estradiol (E2) is accelerated by gonadotropins which then promotes the growth of granular cells of follicles and maturation of ovum [2]. Furthermore, in liver E2 stimulates the synthesis of vitellogenin protein (VTG), a precursor of yolk production in ovum [2,3]. The xenobiotics induced endocrine disorders may have destructive effects on health and survival of living animals, and in fish reproductive system, can be distinguished by several indices such as estradiol (E2) which is important in yolk production process [4]. Blood E2 level alterations can be related to the degree of environmental pollution [4] so that, pollutants lower E2 level [5,6], inhibit plasma vitellogenin [6] and early vitellogenesis [5] and finally disturb sexual maturation [4]. These malfunctions may be attributed by the effects of pollutants on the hypothalamo- pituitarygonadal (HPG) axis [7].

Polycyclic aromatic hydrocarbons (PAHs), as environmental pollutants, inhibits estrogen biosynthesis and inactivate estrogen receptors (ER), by aryl hydrocarbon receptors (AhRs) activation [8] and therefore may lead to estrogenic imbalance in target tissues [9]. AhR activation, on the other hand, alters the neurophysiological processes such as, syntheses and secretion of neurotransmitters in specific neural tissue [10]. Since in bonefish, gonadotropin secretion is control by aminergic pathways [11] therefore it seems that neurotransmitters are sensitive to organic pollutants. Naphthalene (NAP) is a simplest PAH compound. NAP and its methylated forms (alkyl naphthalene), as two hydrocarbon constituents of crude oil [12], considered as the most effective environmental pollutant [13] are very toxic for marine organisms [14]. During the sexual maturation, activation of neuroendocrine systems fluctuate the blood level of gonadotropins. Alternatively, gonadotropins secretion is under the control of serotonergic and dopaminergic pathways [15]. Despite of many reports which focused on the negative effects of PAHs on reproduction $[9,16,17]$ the exact mechanism of the pollutant effects is not elucidated, so far The aim of the present research was to investigate the effects of NAP on the level of neurotransmitters engaged in HPG at previtellogenesis and early vitellogenesis stages in fish. Measuring of the levels of neurotransmitters in fish brain may lead to better understanding of physiological and behavioral complexities in encountering pollutant stress during reproduction.

\section{Materials and Methods}

\section{The fish under study}

During January 2012 some 160 healthy Liza klunzingeri female

*Corresponding author: Sara Rastgar, Department of Marine Biology Faculty of Marine Sciences, Khorramshahr University of Marine Science and Technology, Khoozestan, P.O. Box: 669, Iran, Tel: +009807513336707; Fax: +009807513336707; E-mail: bio.rastgar@gmail.com

Received April 25, 2013; Accepted June 26, 2013; Published June 28, 2013

Citation: Yarahmadi Z, Movahedinia A, Savari A, Rassouli MB, Sahraeian M et al. (2013) Can Naphthalene Exposure Stress Alter Brain Biogenic Amine Levels Before and during Vitellogenesis in Liza klunzingeri Fish? J Environ Anal Toxicol 3 : 178. doi:10.4172/2161-0525.1000178

Copyright: (c) 2013 Yarahmadi Z, et al. This is an open-access article distributed under the terms of the Creative Commons Attribution License, which permits unrestricted use, distribution, and reproduction in any medium, provided the original author and source are credited. 
Citation: Yarahmadi Z, Movahedinia A, Savari A, Rassouli MB, Sahraeian M et al. (2013) Can Naphthalene Exposure Stress Alter Brain Biogenic Amine Levels Before and during Vitellogenesis in Liza klunzingeri Fish? J Environ Anal Toxicol 3: 178. doi:10.4172/2161-0525.1000178

Page 2 of 6

fish, weighted $96.7 \pm 2.77 \mathrm{~g}$, were caught at Khowr-e-Musa Estuary, located at the northern littoral of Persian Gulf (Khuzestan, Iran) and transferred to the Marine Fish Research Center in Imam Khomeini Port. To adapt to normal light and temperature, they were kept in 300 liter tanks for one week and fed for $1 \%$ of their body weight up to 24 hours before sampling.

\section{Experimental design}

In the experiment, an injection and implant of a certain dose of pollutants was used. Dose selection was based upon the previous studies conducted to evaluate PAHs toxicological effects in which, after PAH injection, fish bile PAHs contents were similar to those that naturally exposed to PAH [18-21]. To study the short-term effect of NAP, 80 fish were divided into control and test groups $(n=40)$. Under anesthesia (0.2\% 2-phenoxyethanol), test fish were weighed and then injected (ip) $50 \mathrm{mg} / \mathrm{kg}$ NAP soluble in $2 \mu \mathrm{l} / \mathrm{g}$ sunflower oil. The control fish were injected $2 \mu \mathrm{l} / \mathrm{g}$ sunflower oil. After 3 hours, the blood, brain, and gonads of all fish were sampled. In order to study the long-term effect of NAP, control and test groups $(\mathrm{n}=40)$ were anesthetized, weighed and then, in each fish, an amount of $50 \mathrm{mg} / \mathrm{kg}$ NAP soluble in $10 \mu \mathrm{l} / \mathrm{g}$ coconut oil was implanted (ip). The control fish were implanted $10 \mu \mathrm{l} / \mathrm{g}$ coconut oil, as the same manner. After 3 days, the blood, brain, and gonads of all fish were sampled.

\section{Sampling procedure}

In order to determine the plasma E2 level, fish anesthetized and their bloods were pulled out from caudal vein, using a heparinized syringe, centrifuged (6000 rpm for 7 minutes) and then plasma samples rapidly freeze in liquid nitrogen and kept at $-80^{\circ} \mathrm{C}$ until use. Then all fish were decapitated and their brains dissected out. From the removed brains the pituitary, telencephalon (except olfactory lobe), pre-optic area (included optic tract) and hypothalamus [11,22] were separated, weighted and then rapidly freeze in liquid nitrogen and then kept at $-80^{\circ} \mathrm{C}$ until neurotransmitter measurements. To determine the previtellogenic and early vitellogenenic phases, the ovaries were also removed, fixed in Bouin's solution and processed for histological preparation. The paraffin blocks were cut, stained (hematoxiline-eosin) [23] and examined under light microscope.

\section{Plasma 17- $\beta$ estradiol measurement} $[1,24]$

The plasma concentration of E2 was measured by ELISA technique

\section{Assessment of neurotransmitters levels}

To measure the levels of dopamine, serotonin, noradrenalin, 3,4-dihydroxyphenylacetic acid (DOPAC) and 5-hydroxy-3indoleacetic acid (5HIAA) Waters 2695 HPLC technique was used. The HPLC system was equipped with Waters 2465 Electrochemical Detector (Waters Associates). The procedure was as proposed by Míguez et al. and modified by Gesto et al.

The HPLC liquid phase was prepared as a solution made up by $63.9 \mathrm{mM} \mathrm{NaH} \mathrm{PO}_{4}, 0.1 \mathrm{mM} \mathrm{Na} 2$ EDTA (Sigma), $1.63 \mathrm{mM}$ sodium 1-octanosulfate (Merck), and $14.9 \%$ methanol (Merck). The solution was filtrated and degasified before use.

In order to prepare tissue samples for HPLC, each sample was separately homogenized by an MSE $100 \mathrm{~W}$ ultrasonic homogenizer. Then, a volume of liquid phase solution equal to $0.1 \mathrm{ml}$ for pituitary and $0.5 \mathrm{ml}$ for hypothalamus, telencephalon, and the pre-optic area was added to the vial of the tissue, homogenized again, centrifuged at 16000 rmp and the supernatant was separated. After that they were diluted by liquid phase solution (1:1 for telencephalon and pre-optic area and 1:2 for hypothalamus, pituitary tissue did not diluted) [25-27]. Each injection volume was $30 \mu \mathrm{l}$, each sample run time was 15 minutes, each noise was 3 , and the isocratic flow rate was $1.1 \mathrm{ml} / \mathrm{min}$ at room temperature.

\section{Statistical analysis}

To compare serum E2 level and neurotransmitters concentration in control and treatment groups at previtellogenic and early vitellogenenic phases, the Two-way ANOVA was applied. For multiple comparisons, Student-Newman-Keuls was used. The safety coefficient is \%95 $(\mathrm{P}<0.05)$ for the test. Moreover, Sigma plot ver. 11 was used for analyzing the data and drawing the diagrams.

\section{Results}

The Liza klunzingeri fish seemed healthy during short and longterm Exposure to NAP and no difference was observed in their swimming behaviors. Also, no stress-borne mortality happened. In light microscopy examination of the ovaries, previtellogenic and early vitellogenenic stages can be identified.

\section{$17 \beta$-Estradiol}

In short-term exposure the plasma levels of E2 showed no significant difference between control and treatment groups in both previtellogenic and early vitellogenesnic stages. However, in long-term Exposure with NAP, a significant decrease was observed in treatment group $(\mathrm{P}<0.05)$ (Figure 1)

\section{Measurement of Neurotransmitters Concentrations}

\section{Serotonin}

At previtellogenic stage: In response to short-term NAP exposure, serotonine content of telencephalon and hypothalamus increased ( $\mathrm{P} \leq$ 0.05), (Table 1) and 5-HT content of pituitary decrease significantly ( $\mathrm{P} \leq$ 0.05), (Table 1). In long-term NAP exposed fishes, there was a significant decrease in serotonine content of pre-optic area and hypothalamus $(\mathrm{P}$ $\leq 0.05$ ), (Table 2). Also, significant decrease of 5-HIAA was observed in the four regions at pervitellogenic stage during the short-term NAP exposure while during the long-term exposure, 5-HIAA level was significantly decreased in pituitary and increased in hypothalamus and the pre-optic area $(\mathrm{P} \leq 0.05)$, (Table 1 and 2 ).
Short -term

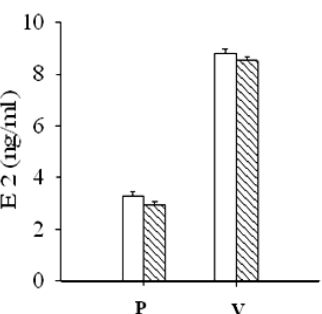

long-term

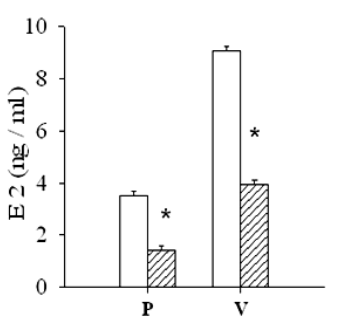

Figure 1: Effect of naphthalene treatment on the response of plasma $17 \beta$ estradiol to Short -term (3hr) or long- term $(72 \mathrm{hr})$ stress stimuli. P: previtellogenic stage. V: early vitellogenesnic stage. White bars: control. Shaded bars: naphthalene treatment. .: indicatea significant difference from the control group $(p<0 / 05)$. 
Citation: Yarahmadi Z, Movahedinia A, Savari A, Rassouli MB, Sahraeian M et al. (2013) Can Naphthalene Exposure Stress Alter Brain Biogenic

Vitellogenesnic stage: In response to short-term NAP exposure, 5 -HT content of telencephalon increased $(\mathrm{P} \leq 0.05)$, (Table 1$)$. The preoptic area, in long-term exposure, 5-HIAA level showed a significant decrease $(\mathrm{P} \leq 0.05)$, (Table 2).

\section{Dopamine}

At previtellogenic stage: The results showed a significant increase of dopamine concentration in telencephalon and the pre-optic area after short-term exposing with NAP $(\mathrm{P} \leq 0.05)$, (Table 1$)$. Moreover, three days after exposing with NAP, there was a significant decrease in dopamine concentration in telencephalon and the pre-optic area. In contrast, a significant increase of this monoamine was observed in hypothalamus and pituitary ( $\mathrm{P} \leq 0.05)$, (Table 2$)$. DOPAC concentration showed a significant increase in pre-optic area during the short-term stress $(\mathrm{P}<0.05)$, (Table 1). The average DOPAC concentration had a significantly increased in all areas of telencephalon, the pre-optic area, hypothalamus, and pituitary during the long-term exposuring with NAP $(\mathrm{P}<0.05)$, (Table 2$)$.

Vitellogenesnic stage: This neurotransmitter showed no significant difference in all areas in short-term exposing $(\mathrm{P}>0.05)$, (Table 1). For the long-term exposing, the average dopamine concentration showed a significant increase only in hypothalamus $(\mathrm{P} \leq 0.05)$, (Table 2$)$. The results of studying the long-term stress in the fish at vitellogenic stage showed a significant decrease in oxidized dopamine metabolite concentration in telencephalon, and its significant increase in hypothalamus $(\mathrm{P}<0.05)$, (Table 2).

Noradrenalin: Noradrenalin showed the least amount of change, and its changes were limited to hypothalamus and pituitary at previtellogenic stage. The results revealed a significant increase of noradrenalin in hypothalamus at previtellogenic stage in both exposure with NAP $(\mathrm{P} \leq 0.05)$, (Table 1 and 2). However, at previtellogenic stage, significant decrease of noradrenalin was observed in pituitary during short and long- term $(\mathrm{P} \leq 0.05)$, (Table 1 and 2 ).

\section{Discussion}

\section{Estradiol}

The results of the present research showed a significant decrease of $17 \beta$-estradiol levels at both previtellogenic and vitellogenic stages after the long-term NAP stress. Similar findings are reported on the effects of beta-naphthoflaven on Coho salmon [28] and BaP on Flander fish [9], rainbow trout [1] and Atlantic croaker [4]. PAHs are lipophilic compounds that may be stored in the tissues enriched in lipids, e.g., gonads and brain; therefore, they can have many effects on these organs $[29,30]$. The effect of NAP on $17 \beta$-estradiol may be due to either its interaction with the HPG axis or changes in E2 synthesis.

It is has been suggested that NAP inhibit the synthesis of the three enzymes involved in 17 $\beta$-estradiol production [9], has anti-esterogenic activities and compete for bonding with ERs, and probably by prevention of expression of genes related to aromatase enzyme and by disturbance in yolk production reduce vitellogenin [31]. Even more, the results obtained from the present research indicate that NAP-induced E2 reduction is more remarkable at previtellogenic stage. Therefore, it can be concluded that previtellogenic stage is more susceptible to chemical stress than vitellogenic stage $[27,32]$.

\section{Serotonin}

The cell bodies of serotonergic neurons were mostly located in diencephalon and mesencephalon, being more concentrated in hypothalamus [11]. Therefore, it can be expected that, when treated with NAP, more turbulence in serotonin system is observed at these areas. In telencephalon and hypothalamus, an increase in serotonin, a decrease in its metabolite concentration, and a decrease in 5-HIAA/5HT ratio were occurred at previtellogenic stage after a 3-hour exposure with NAP (Figure 2). To explain this suggestion, the ratio of the amount of main metabolite of a transmitter to the amount of transmitter can be applied as an index for estimating the amount of neurotransmitter release. This ratio is an index of synaptic activity; high ratios indicate high resorption and release or high activity of aminergic neurons, and low ratios show low resorption and release or low activity of aminergic neurons [33-37]. It seems that decrease in serotonin activity is due to the decrease in serotonin catabolism. It is likely that non functional MAO enzyme inhibit serotonin convergence into 5-HIAA [38,39]. Since, in short-term NAP exposure at previtellogenic stage, a decrease in serotonin metabolite and also in 5-HIAA/5-HT ratio occurred at the pre-optic area (Figure 2), with no change in serotonin content it can be concluded that the activity of serotonergic neurons may prevented by NAP [21]. NAP may have a preventive effect on serotonin catabolism at the pre-optic area.

At previtellogenic, 72 hours after treatment with NAP, a decrease in hypothalamus serotonin content occurred without any change in its metabolite and in the ratio of 5-HIAA/5-HT (Figure 2). Any disorder in the function of the enzymes synthesizing serotonin, e.g., tryptophan hydroxylase due to NAP [40].

Since NAP has narcotic characteristics [41], and the transporters of biogenic amines, such as serotonin, are the primary targets of narcotics in neurons $[11,42,43]$, these compounds commonly bond with transporters and prevent the activity of neurotransmitters. Therefore, they may change the concentration of neurotransmitters,
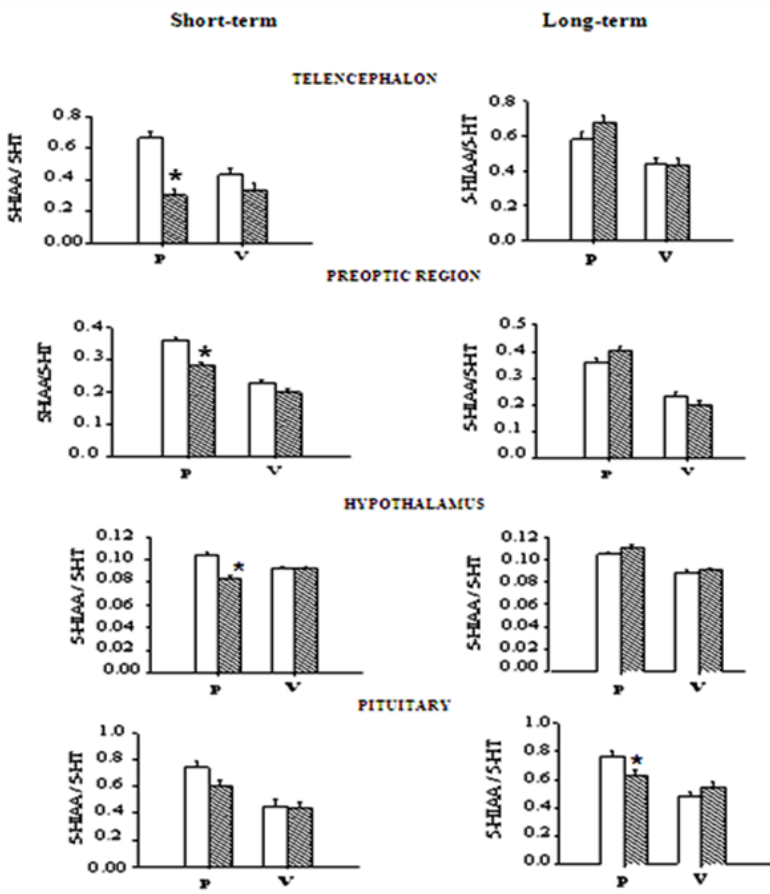

Figure 2: Effect of naphthalene treatment on the response of 5-HIAA/5$\mathrm{HT}$ to Short and long- term stress stimuli. P: previtellogenic stage. V: early vitellogenesnic stage. White bars: control. Shaded bars: naphthalene treatment : indicate a significant difference from the control group $(p<0 / 05)$ 
Citation: Yarahmadi Z, Movahedinia A, Savari A, Rassouli MB, Sahraeian M et al. (2013) Can Naphthalene Exposure Stress Alter Brain Biogenic Amine Levels Before and during Vitellogenesis in Liza klunzingeri Fish? J Environ Anal Toxicol 3: 178. doi:10.4172/2161-0525.1000178

Page 4 of 6

\begin{tabular}{|c|c|c|c|c|c|c|c|c|c|}
\hline & & \multicolumn{8}{|c|}{ Short-term exposure to NAP } \\
\hline & & \multicolumn{4}{|c|}{ Previtellogenic stage } & \multicolumn{4}{|c|}{ Vitelloginic stage } \\
\hline & & Tel & Hypo & Pitu & PO & Tel & Hypo & Pitu & PO \\
\hline \multirow{2}{*}{ 5-HT } & c & $572.96 \pm 66.53$ & $1834.02 \pm 21.81$ & $55.77 \pm 4.25$ & $295.34 \pm 3.1$ & $491.33 \pm 1.85$ & $1351.66 \pm 15.89$ & $24.01 \pm 0.55$ & $238.78 \pm 2.14$ \\
\hline & $E$ & $1108.36 \pm 3.22 \uparrow$ & $1964.33 \pm 9.79 \uparrow$ & $46.73 \pm 1.82 \downarrow$ & $305.08 \pm 3.62$ & $650.44 \pm 5.88 \uparrow$ & $1391.86 \pm 4.32$ & $22.51 \pm 0.64$ & $242.40 \pm 3.06$ \\
\hline \multirow[t]{2}{*}{ 5-HIAA } & C & $368.6 \pm 5.16$ & $190.34 \pm 3.17$ & $41.16 \pm 3.49$ & $86.61 \pm 2.40$ & $212.43 \pm 1.82$ & $123.84 \pm 4.38$ & $7.91 \pm 0.42$ & $54.71 \pm 2.21$ \\
\hline & E & $334.5 \pm 5.16 \downarrow$ & $163.13 \pm 2.37 \downarrow$ & $28.13 \pm 1.27 \downarrow$ & $56.35 \pm 2.06 \downarrow$ & $217.92 \pm 1.11$ & $127.53 \pm 0.26$ & $9.86 \pm 0.12$ & $48.38 \pm 1.45$ \\
\hline \multirow{2}{*}{ DA } & C & $185.53 \pm 2.41$ & $1645.89 \pm 55.02$ & $293.24 \pm 3.56$ & $145.87 \pm 8.35$ & $107.97 \pm 1.93$ & $996.95 \pm 1.76$ & $207.27 \pm 1.70$ & $112.33 \pm 1.45$ \\
\hline & $E$ & $218.72 \pm 1.15 \uparrow$ & $1763.96 \pm 218.65$ & $304.61 \pm 7.99$ & $183.13 \pm 2.83 \uparrow$ & $132.34 \pm 19.63$ & $1002.28 \pm 0.68$ & $190.22 \pm 5.82$ & $117.03 \pm 1.06$ \\
\hline \multirow{2}{*}{ DOPAC } & C & $11.66 \pm 0.44$ & $11.10 \pm 0.46$ & $34.77 \pm 2.48$ & $6.17 \pm 0.72$ & $6.56 \pm 0.47$ & $5.73 \pm 0.28$ & $13.07 \pm 1.21$ & $2.01 \pm 0.04$ \\
\hline & $E$ & $14.20 \pm 1.69$ & $12.46 \pm 0.75$ & $31.86 \pm 2.87$ & $4.23 \pm 0.21 \uparrow$ & $6.93 \pm 0.23$ & $6.66 \pm 3.69$ & $8.68 \pm 0.77$ & $2.23 \pm 0.13$ \\
\hline \multirow{2}{*}{ NA } & C & $679.18 \pm 5.52$ & $678.69 \pm 5.73$ & $101.12 \pm 1.53$ & $230.73 \pm 2.30$ & $604.56 \pm 2.73$ & $614.33 \pm 2.96$ & $73.76 \pm 2.13$ & $198.56 \pm 0.78$ \\
\hline & $\mathrm{E}$ & $753.53 \pm 97.70$ & $695.82 \pm 3.22 \uparrow$ & $82.28 \pm 1.54 \downarrow$ & $229.83 \pm 2.08$ & $593.03 \pm 3.02$ & $607.13 \pm 1.04$ & $67.94 \pm 2.96$ & $193.21 \pm 1.59$ \\
\hline
\end{tabular}

Tel $=$ Telencephalon, Hypo $=$ Hypothalamus, Pitu $=$ Hypophysis, $\mathrm{PO}=$ Preoptic area

5-HT= Serotonine, 5-HIAA= 5-hydroxy-3-indoleacetic acid, DA = Dopamine, DOPAC= 3,4-dihydroxyphenylacetic acid, NA. = Noradrenalin, C= Control, E= Exposed whit NAP

$\uparrow$ significantly increased in compare with control, $\downarrow$ significantly decreased in compare with control,

Table 1: Alterations of transmitter's content in certain regions of brain in female fish exposed to NAP.

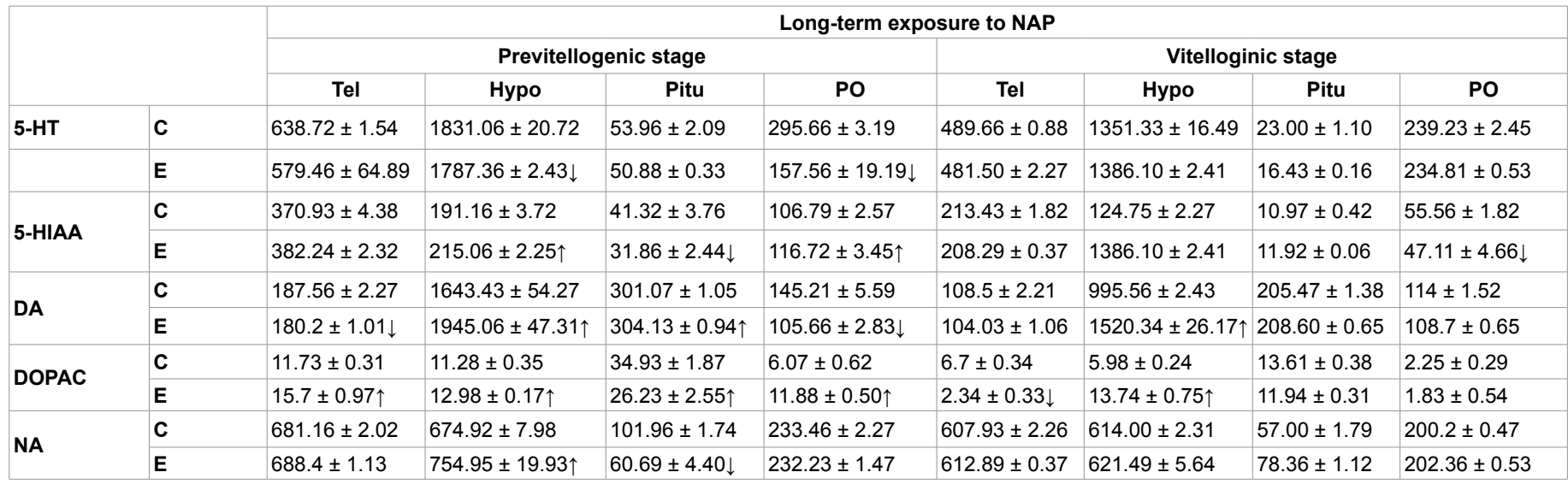

Tel $=$ Telencephalon, Hypo $=$ Hypothalamus, Pitu $=$ Hypophysis, $\mathrm{PO}=$ Preoptic area

5-HT= Serotonine, 5-HIAA= 5-hydroxy-3-indoleacetic acid, DA = Dopamine, DOPAC= 3,4-dihydroxyphenylacetic acid, NA. = Noradrenalin, C= Control, E= Exposed whit NAP

$\uparrow$ significantly increased in compare with control, $\downarrow$ significantly decreased in compare with control

Table 2: Alterations of transmitter's content in certain regions of brain in female fish exposed to NAP

and disturb the normal equilibrium of monoamine transmitters [44]. Hence, the decrease of serotonin concentration and 5-HIAA/5HT ratio in pituitary compared to control samples at previtellogenic stage in short- term may be induced by disturbance in the function of serotonin vesicular transporters during treatment with NAP (Figure 2). Although it is likely that NAP decreases the efficiency of the enzymes synthesizing serotonin, including tryptophan hydroxylase [45], the occurrence of each possibility may decrease serotonin metabolite and serotonin activity following a decrease in serotonin content.

\section{Dopamine}

Since, in vertebrate, reproduction is under the control of HPG axis and aminergic system indirectly regulates gonadal functions $[15,35]$ disfunctions of aminergic systems may disturb vitellogensis $[27,46]$. After 72 hours, the amount of DA decreased in telencephalon and the pre-optic area at previtellogenic stage during exposuring with NAP. There are a few possibilities for decreasing DA: (1) as tyrosine convert into catecholamine dopamine by tyrosine hydroxylase enzyme after absorption in neurons, it is probable that NAP decreases dopamine production by preventing from its activity [47], and (2) NAP may decrease DA vesicular absorption in presynaptic neuron through its agonistic effect on DA transporters [48]. Since catabolism rate increases simultaneous with DA decrease, the occurrence of each possibility seems quite rare. In fact, DA decreasing, when it exposure with NAP, results from increasing the absorption rate and consumption of this neurotransmitter, In other words Increased dopaminergic activity in these areas (Figure 2).

Regarding the changes of dopamine system at the pre-optic area, during its 3-hour exposure with NAP at previtellogenic stage. Gesto et al. reported opposite results in immature rainbow fish. The reason for such different results may be attributed to fish sexual stage; because fish prepare to enter into yolk production at previtellogenic stage. Thus, in addition to NAP effect, hormonal feedbacks and physiologic changes in maturity may influence dopamine variations. Since the ecology and genetics of these species may differentiate the structure of the brain area in various species, difference in NAP storage pattern, and consequently in its effects on the area, seems possible.

It may be said that long-term exposure with NAP has decreased dopamine system activity through stimulating synthesis and resorption 
Citation: Yarahmadi Z, Movahedinia A, Savari A, Rassouli MB, Sahraeian M et al. (2013) Can Naphthalene Exposure Stress Alter Brain Biogenic Amine Levels Before and during Vitellogenesis in Liza klunzingeri Fish? J Environ Anal Toxicol 3: 178. doi:10.4172/2161-0525.1000178

Page 5 of 6

and dopamine catabolism, or has decreased dopamine concentration by disordering the function of monoamine oxidase (MAO) enzymes and stimulating such enzymes for more dopamine oxidation [38,39].

In long-term NAP exposure, DA content and DOPAC metabolite increased in hypothalamus at both previtellogenic and vitellogenic stages. It means that the synthesis, release, and catabolism of dopamine were increased.

\section{Noradrenalin}

The amount of noradrenalin in hypothalamus increased at previtellogenic stage within 3 and 72 hours after exposuring with NAP. Gesto et al. reported similar results when they studied the effects of NAP on brain neurotransmitters in rainbow trout. Since noradrenergic inputs reach mesencephalon (hypothalamus) from hindbrain, it appears that NAP increases the concentration of noradrenalin through its stimulating effect on its synthesis. Moreover, as DA is the precursor of noradrenalin synthesis and amino acids are bounded between these two neurotransmitters [49], it may be said that noradrenalin changes follow dopamine changes in hypothalamus after 72 hours. As the cellular masses of noradrenalin neurons are located at locus coeruleous in brainstem and their axons extend to pituitary [11,50], it appears that noradrenalin decrease is induced by NAP at both 3 and 72 hour exposures preventive effect on noradrenalin production in brainstem or its release from the axons of adrenergic neurons in pituitary. Despite the fact that intermediate metabolites are bounded between dopamine and noradrenalin, it seems that different mechanisms arising from NAP activity indirectly influence the metabolism of each catecholamine in pituitary neural terminals.

Treatment with NAP disturbed the balance of biogenic amines in some parts of fish brains at previtellogenic and vitellogenic stages. However, the changes were more evident at previtellogenic stage. The patterns of these changes may vary due to aminergic neurons variance, exposure duration, and sexual stages. The results show that NAP, as an organic pollutant, has a high potential for creating extensive changes in brain monoamine system. The complex of aminergic neurotransmitters related to hypothalamus, pituitary, and the pre-optic area are involved in pituitary endocrine activities such as regulating GtH hormone, synchronization of important occurrence in reproduction $[11,35]$. The results indicate most changes in the aminergic system in this area.

The feedback effects of steroids on the hormonal task of pituitaryhypothalamus are well recognized [51]. The steroids released into the body may influence the increase or decrease of pituitary secretions, at least by positively or negatively affecting the controlling factors of these secretions, including neurotransmitters $[15,52]$. Since NAP treatment has caused changes in $17 \beta$-estradiol levels in plasma, it is likely that level changes of this hormone has led to the disturbance of brain monoamine system due to NAP treatment through positive or negative feedbacks. NAP may disturb yolk production process by directly influencing the gonadal tissue or the HPG axis.

\section{Conclusion}

The results of the present study indicate that, in previtellogenic stage of fish reproductive period, NAP may targets serotonergic and dopaminergic systems in short-term and long-term exposure, respectively. Moreover, NAP induced changes in $17 \beta$-estradiol probably is due to the consequence of the effects of NAP on aminergic systems which alternatively alter the output of HPG axis. Disturbance of yolk production endangers the successful reproduction in fish.

\section{Acknowledgements}

We would like to express our special thanks to Dr. Manuel Gesto from Vigo University of Spain, Dr. Sarkaki for useful suggestions and assistance during sampling and analysis. This project was performed in the Khorramshahr University of Marine Science and Technology as the M.Sc. course thesis that was authorized in Faculty of Marine Sciences.

\section{References}

1. Tintos A, Gesto M, Alvarez R, Míguez JM, Soengas JL (2006) Interactive effects of naphthalene treatment and the onset of vitellogenesis on energy metabolism in liver and gonad, and plasma steroid hormones of rainbow trout (Oncorhynchus mykiss). Comp Biochem Physiol C Toxicol Pharmacol 144 155-165.

2. Davies B, Bromage N, Swanson P (1999) The brain-pituitary-gonadal axis of female rainbow trout Oncorhynchus mykiss: effects of photoperiod manipulation1. Gen Comp Endocrinol 115: 155-166.

3. Tyler C, Van der Eerden B, Jobling S, Panter G, Sumpter J (1996) Measurement of vitellogenin, a biomarker for exposure to oestrogenic chemicals, in a wide variety of cyprinid fish. Journal of Comparative Physiology B 166: 418-426.

4. Thomas P, Budiantara L (1995) Reproductive life history stages sensitive to oil and naphthalene in Atlantic croaker. Marine Environmental Research 39: 147-150.

5. Anderson MJ, Miller MR, Hinton DE (1996) In vitro modulation of 17-[beta]estradiol-induced vitellogenin synthesis: Effects of cytochrome P4501A1 inducing compounds on rainbow trout (Oncorhynchus mykiss) liver cells Aquatic Toxicology 34: 327-350.

6. Vaccaro E, Meucci V, Intorre L, Soldani G, Di Bello D, et al. (2005) Effects of 17beta-estradiol, 4-nonylphenol and PCB 126 on the estrogenic activity and phase 1 and 2 biotransformation enzymes in male sea bass (Dicentrarchus labrax). Aquat Toxicol 75: 293-305.

7. Teles M, Oliveira M, Pacheco M, Santos MA (2005) Endocrine and metabolic changes in Anguilla anguilla L. following exposure to beta-naphthoflavone--a microsomal enzyme inducer. Environ Int 31: 99-104.

8. Aluru N, Vuori K, Vijayan MM (2005) Modulation of Ah receptor and CYP1A1 expression by alpha-naphthoflavone in rainbow trout hepatocytes. Comp Biochem Physiol C Toxicol Pharmacol 141: 40-49.

9. Rocha Monteiro PR, Reis-Henriques MA, Coimbra J (2000) Polycyclic aromatic hydrocarbons inhibit in vitro ovarian steroidogenesis in the flounder (Platichthys flesus L.). Aquat Toxicol 48: 549-559.

10. Yamauchi M, Kim EY, Iwata $H$, Tanabe $S$ (2005) Molecular characterization of the aryl hydrocarbon receptors (AHR1 and AHR2) from red seabream (Pagrus major). Comp Biochem Physiol C Toxicol Pharmacol 141: 177-187.

11. Cerdá-Reverter J M, Canosa LF (2009) Neuroendocrine systems of the fish brain. Fish Physiol 28: 3-74.

12. Aas E, Baussant T, Balk L, Liewenborg B, Andersen OK (2000) PAH metabolites in bile, cytochrome P4501A and DNA adducts as environmenta risk parameters for chronic oil exposure: a laboratory experiment with Atlantic cod. Aquat Toxicol 51: 241-258.

13. Lee RF, Anderson JW (2005) Significance of cytochrome P450 system responses and levels of bile fluorescent aromatic compounds in marine wildlife following oil spills. Mar Pollut Bull 50: 705-723.

14. Vijayavel K, Balasubramanian MP (2006) Changes in oxygen consumption and respiratory enzymes as stress indicators in an estuarine edible crab Scylla serrata exposed to naphthalene. Chemosphere 63: 1523-1531.

15. Hernandez-Rauda R, Aldegunde M (2002) Changes in dopamine norepinephrine and serotonin levels in the pituitary, telencephalon and hypothalamus during gonadal development of male Lutjanus argentiventris (Teleostei). Marine Biology 141: 209-216.

16. Matthiessen P, Allen Y, Allchin C, Feist S, Kirby M, et al. (1998) Oestrogenic endocrine disruption in flounder (Platichthys flesus L.) from United Kingdom estuarine and marine waters. CEFAS,

17. Hoffmann JL, Oris JT (2006) Altered gene expression: a mechanism fo reproductive toxicity in zebrafish exposed to benzo[a]pyrene. Aquat Toxicol 78 332-340.

18. Wilson JM, Vijayan MM, Kennedy CJ, Iwama GK, Moon TW (1998) beta- 
Citation: Yarahmadi Z, Movahedinia A, Savari A, Rassouli MB, Sahraeian M et al. (2013) Can Naphthalene Exposure Stress Alter Brain Biogenic Amine Levels Before and during Vitellogenesis in Liza klunzingeri Fish? J Environ Anal Toxicol 3: 178. doi:10.4172/2161-0525.1000178

Naphthoflavone abolishes interrenal sensitivity to ACTH stimulation in rainbow trout. J Endocrinol 157: 63-70.

19. Pacheco M, Santos MA (1998) Induction of liver EROD and erythrocytic nuclea abnormalities by cyclophosphamide and PAHs in Anguilla anguilla L. Ecotoxico Environ Saf 40: 71-76.

20. Escartin E, Porte C (1999) Assessment of PAH pollution in coastal areas from the NW Mediterranean through the analysis of fish bile. Marine pollution bulletin 38: $1200-1206$

21. Gesto M, Soengas JL, Míguez JM (2008) Acute and prolonged stress responses of brain monoaminergic activity and plasma cortisol levels in rainbow trout are modified by PAHs (naphthalene, beta-naphthoflavone and benzo(a)pyrene) treatment. Aquat Toxicol 86: 341-351.

22. Butler AB, Hodos W (2005) Comparative vertebrate neuroanatomy: evolution and adaptation. Wiley Online Library.

23. Barciela P, Soengas J, Rey P, Aldegunde M, Rozas G (1993) Carbohydrate metabolism in several tissues of rainbow trout, Oncorhynchus mykiss, is modified during ovarian recrudescence. Comparative Biochemistry and Physiology Part B: Comparative Biochemistry 106: 943-948.

24. Tintos A, Gesto M, Míguez, JM ,Soengas JL (2007) Naphthalene treatment alters liver intermediary metabolism and levels of steroid hormones in plasma of rainbow trout (Oncorhynchus mykiss). Ecotoxicol Environ Saf 66: 139-147.

25. Míguez JM, Aldegunde M, Paz-Valiñas L, Recio J, Sánchez-Barceló E (1999) Selective changes in the contents of noradrenaline, dopamine and serotonin in rat brain areas during aging. J Neural Transm 106: 1089-1098.

26. Gesto M, Tintos A, Soengas J L,Míguez J M (2006) Effects of acute and prolonged naphthalene exposure on brain monoaminergic neurotransmitters in rainbow trout (Oncorhynchus mykiss). Comp Biochem Physiol C Toxicol Pharmacol 144: 173-183.

27. Gesto M, Tintos A, Alvarez R, Soengas JL, Míguez JM (2009) Alterations in the brain monoaminergic neurotransmitters of rainbow trout related to naphthalene exposure at the beginning of vitellogenesis. Fish Physiol Biochem 35: 453-465.

28. Afonso LO, Campbell PM, Iwama GK, Devlin RH, Donaldson EM (1997) The effect of the aromatase inhibitor fadrozole and two polynuclear aromatic hydrocarbons on sex steroid secretion by ovarian follicles of coho salmon. Gen Comp Endocrinol 106: 169-174.

29. Meador JP, Stein JE, Reichert WL, Varanasi U (1995) Bioaccumulation of polycyclic aromatic hydrocarbons by marine organisms. Rev Environ Contam Toxicol 143: 79-165.

30. Meador JP, Sommers FC, Ylitalo GM, Sloan CA (2006) Altered growth and related physiological responses in juvenile Chinook salmon (Oncorhynchus tshawytscha) from dietary exposure to polycyclic aromatic hydrocarbons (PAHs). Can J Fish Aquat Sci 63: 2364-2376

31. Scholz S, Mayer I (2008) Molecular biomarkers of endocrine disruption in smal model fish. Mol Cell Endocrinol 293: 57-70.

32. Nicolas JM (1999) Vitellogenesis in fish and the effects of polycyclic aromatic hydrocarbon contaminants. Aquatic Toxicology 45: 77-90.

33. Shannon N, Gunnet J, Moore K(1986) A Comparison of Biochemical Indices of 5-Hydroxytryptaminergic Neuronal Activity Following Electrical Stimulation of the Dorsal Raphe Nucleus. J Neurochem 47: 958-965.

34. Dulka JG, Sloley BD, Stacey NE, Peter RE (1992) A reduction in pituitary dopamine turnover is associated with sex pheromone-induced gonadotropin secretion in male goldfish. Gen Comp Endocrinol 86: 496-505.

35. Hernandez-Rauda R, Otero J, Rey P, Rozas G, Aldegunde M (1996) Dopamine and serotonin in the trout (Oncorhynchus mykiss) pituitary: main metabolites and changes during gonadal recrudescence. Gen Comp Endocrinol 103: 13 23.

36. Oades RD, Röpcke B, Henning U, Klimke A (2005) Neuropsychological measures of attention and memory function in schizophrenia: relationships with symptom dimensions and serum monoamine activity. Behav Brain Funct 1: 14

37. Fillenz M (2005) In vivo neurochemical monitoring and the study of behaviour. Neurosci Biobehav Rev 29: 949-962.

38. Thull U, Testa B (1994) Screening of unsubstituted cyclic compounds as inhibitors of monoamine oxidases. Biochem Pharmacol 47: 2307-2310.

39. Santana L, González-Díaz H, Quezada E, Uriarte E, Yáñez M, et al. (2008) Quantitative structure-activity relationship and complex network approach to monoamine oxidase A and B inhibitors. J Med Chem 51: 6740-6751.

40. Khan IA, Thomas $P$ (2004) Aroclor 1254 inhibits tryptophan hydroxylase activity in rat brain. Arch Toxicol 78: 316-320.

41. Barron MG, Heintz R, Rice SD (2004) Relative potency of PAHs and heterocycles as aryl hydrocarbon receptor agonists in fish. Mar Environ Res 58: $95-100$.

42. Amara SG, Sonders MS (1998) Neurotransmitter transporters as molecula targets for addictive drugs. Drug Alcohol Depend 51: 87-96.

43. Canosa LF, Chang JP, Peter RE (2007) Neuroendocrine control of growth hormone in fish. Gen Comp Endocrinol 151: 1-26.

44. Melikian HE (2004) Neurotransmitter transporter trafficking: endocytosis, recycling, and regulation. Pharmacol Ther 104: 17-27.

45. Khan IA, Thomas $P$ (2001) Disruption of neuroendocrine control of luteinizing hormone secretion by aroclor 1254 involves inhibition of hypothalamic tryptophan hydroxylase activity. Biol Reprod 64: 955-964.

46. Crump KL, Trudeau VL (2009) Mercury-induced reproductive impairment in fish. Environ Toxicol Chem 28: 895-907.

47. Choksi NY, Kodavanti PR, Tilson HA, Booth RG (1997) Effects of polychlorinated biphenyls (PCBs) on brain tyrosine hydroxylase activity and dopamine synthesis in rats. Fundam Appl Toxicol 39: 76-80.

48. Mariussen E, Morch Andersen J, Fonnum F (1999) The effect of polychlorinated biphenyls on the uptake of dopamine and other neurotransmitters into rat brain synaptic vesicles. Toxicol Appl Pharmacol 161: 274-282.

49. Wu HF, Lin YP (2000) Study of ion-molecule reactions and collisionally-activated dissociation of dopamine and adrenaline by an ion trap mass spectrometer with an external ionization source. Eur J Mass Spectrom 6: 65-78.

50. Meek J (1994) Catecholamines in the brains of Osteichthyes (bony fishes). Phylogeny and development of catecholamine systems in the CNS of vertebrates (Smeets WJAJ, Reiner A, eds), 41994) 49-76.

51. Peter R, Yu K (1997) Neuroendocrine regulation of ovulation in fishes: basic and applied aspects. Reviews in Fish Biology and Fisheries 7: 173-197.

52. DiBattista JD, Anisman H, Whitehead M, Gilmour KM (2005) The effects of cortisol administration on social status and brain monoaminergic activity in rainbow trout Oncorhynchus mykiss. J Exp Biol 208: 2707-2718. 